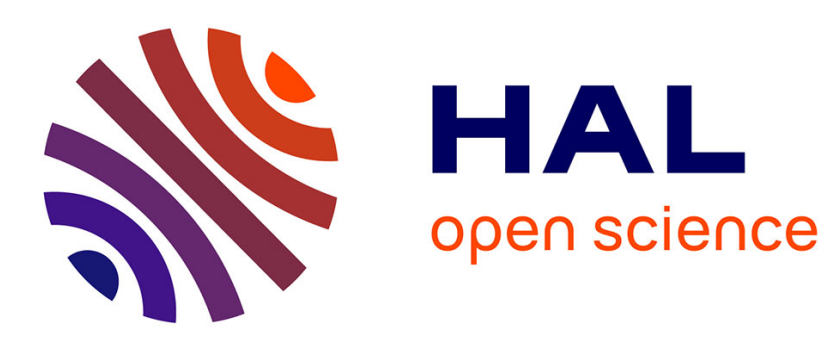

\title{
Leptin synergistically enhances the anti-apoptotic and growth-promoting effects of acid in OE33 oesophageal adenocarcinoma cells in culture
}

\author{
Ian L.P. Beales, Olorunseun O. Ogunwobi
}

\section{- To cite this version:}

Ian L.P. Beales, Olorunseun O. Ogunwobi. Leptin synergistically enhances the anti-apoptotic and growth-promoting effects of acid in OE33 oesophageal adenocarcinoma cells in culture. Molecular and Cellular Endocrinology, 2007, 274 (1-2), pp.60. 10.1016/j.mce.2007.05.017 . hal-00531934

\author{
HAL Id: hal-00531934 \\ https://hal.science/hal-00531934
}

Submitted on 4 Nov 2010

HAL is a multi-disciplinary open access archive for the deposit and dissemination of scientific research documents, whether they are published or not. The documents may come from teaching and research institutions in France or abroad, or from public or private research centers.
L'archive ouverte pluridisciplinaire HAL, est destinée au dépôt et à la diffusion de documents scientifiques de niveau recherche, publiés ou non, émanant des établissements d'enseignement et de recherche français ou étrangers, des laboratoires publics ou privés. 


\section{Accepted Manuscript}

Title: Leptin synergistically enhances the anti-apoptotic and growth-promoting effects of acid in OE33 oesophageal adenocarcinoma cells in culture

Authors: Ian L.P. Beales, Olorunseun O. Ogunwobi

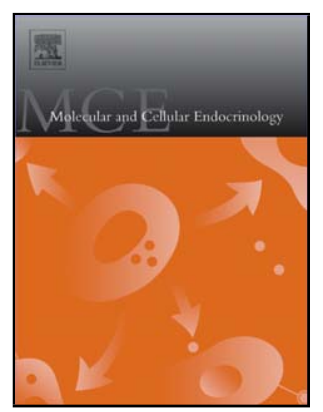

PII:

S0303-7207(07)00216-X

DOI: doi:10.1016/j.mce.2007.05.017

Reference: MCE 6668

To appear in: $\quad$ Molecular and Cellular Endocrinology

Received date: $\quad 26-2-2007$

Revised date: 29-5-2007

Accepted date: $\quad$ 29-5-2007

Please cite this article as: Beales, I.L.P., Ogunwobi, O.O., Leptin synergistically enhances the anti-apoptotic and growth-promoting effects of acid in OE33 oesophageal adenocarcinoma cells in culture, Molecular and Cellular Endocrinology (2007), doi:10.1016/j.mce.2007.05.017

This is a PDF file of an unedited manuscript that has been accepted for publication. As a service to our customers we are providing this early version of the manuscript. The manuscript will undergo copyediting, typesetting, and review of the resulting proof before it is published in its final form. Please note that during the production process errors may be discovered which could affect the content, and all legal disclaimers that apply to the journal pertain. 


\title{
Leptin synergistically enhances the anti-apoptotic and growth-promoting effects of acid in OE33 oesophageal adenocarcinoma cells in culture
}

\author{
Ian L. P. Beales ${ }^{1,2}$ and Olorunseun O. Ogunwobi ${ }^{2}$ \\ Affiliations: \\ ${ }^{1}$ Department of Gastroenterology, Norfolk and Norwich University Hospital, \\ Norwich, NR4 7UZ, UK \\ ${ }^{2}$ Biomedical Research Centre, School of Medicine, Health Policy and Practice, \\ University of East Anglia, Norwich, NR4 7TJ, UK \\ Address correspondence to: \\ Dr Beales, \\ School of Medicine, Health Policy and Practice, \\ University of East Anglia, \\ Norwich, NR4 7TJ, United Kingdom. \\ Tel. +441603591003 \\ Fax. +44 1603593752 \\ E-mail: $\underline{\text { i.beales@uea.ac.uk }}$
}

Running title: leptin and acid in oesophageal adenocarcinoma 
Key Words: apoptosis, Akt, Barrett's oesophagus, cyclo-oxygenase, epidermal growth factor receptor, leptin, mitogen activated protein kinase, oesophageal cancer.

Abbreviations used: BO, Barrett's oesophagus; COX, cyclo-oxygenase; DMEM, Dulbecco's modified eagle medium; DMSO, dimethyl sulfoxide; OAC, oesophageal adenocarcinoma, ELISA, enzyme-linked immunosorbent assay; EGFR, epidermal growth factor receptor; ERK, p42/44 extracellular signal regulated kinase; FBS, foetal bovine serum; G-Gly, glycineextended gastrin; JAK, Janus tyrosine kinase; JNK, c-Jun $\mathrm{NH}_{2}$-terminal kinase; MAP, mitogenactivated protein kinase; MTT, 3-[4, 5-dimethylthiazol-2-y-1]-2, 5-diphenyltetrazolium bromide; NSAIDs, non-steroidal anti-inflammatory drugs; p38 MAP kinase, p38 mitogen activated protein kinase PBS, phosphate buffered saline $\mathrm{pH}$ 7.4; PGE2, prostaglandin E2; PI3kinase, phosphatidylinositol 3'-kinase. 


\begin{abstract}
Obesity and gastro-oesophageal reflux are the main predisposing factors for oesophageal adenocarcinoma. We have examined the effects of transient acid exposure and leptin on OE33 oesophageal adenocarcinoma cells. Leptin and acid individually stimulated proliferation and inhibited apoptosis and the combination was synergistic. Leptin receptor protein levels were unchanged by acid exposure. The COX-2 inhibitor NS 398 blocked the effects of acid and leptin but while both acid and leptin individually significantly increased PGE2 production and COX-2 mRNA levels, the combination was not more effective than either stimulant alone. Leptin synergistically enhanced acid-stimulated EGFR and ERK phosphorylation but did not further increase JNK or p38 MAP kinase phosphorylation. Specific EGFR and ERK inhibitors reduced the effects of leptin and acid alone and in combination. The combination of increased circulating leptin levels in obesity and transient reflux of gastric acid may promote oesophageal carcinogenesis by increasing proliferation and inhibiting apoptosis.
\end{abstract}




\section{Introduction}

Oesophageal adenocarcinoma $(\mathrm{OAC})$ is an increasing problem in the developed world (Buttar and Wang, 2004). Although the incidence of squamous cancer of the oesophagus is relatively static, the age-standardised incidence of OAC has increased significantly over the last 30 years (Jemal et al. 2006). The reasons for this increase as well as the molecular pathology of OAC are not fully understood, but because of the generally poor prognosis for this cancer improved understanding of the causes is essential to target preventative and treatment strategies.

Oesophageal adenocarcinoma arises in most, if not all cases, from metaplastic columnar oesophageal epithelium (Barrett's oesophagus (BO)) and all the factors which drive the transformation remain to be elucidated. Increased proliferation and reduced apoptosis of the Barrett's epithelium are believed to be important in the progression of to OAC; the increased cell division and reduced cell death probably allow accumulation and perpetuation of genetic abnormalities leading to malignant transformation. Increased proliferation in $\mathrm{BO}$ is associated with an increased risk of progression to OAC (Buttar and Wang, 2004). Because of this it is important to determine the factors which drive proliferation and inhibit apoptosis in $\mathrm{OAC}$ and $\mathrm{BO}$.

The two main epidemiological risk factors for OAC are obesity (Lagergren et al. 1999b) and symptomatic gastro-oesophageal reflux (Lagergren et al. 1999a). These factors appear to be independent of each other. Experimental studies have shown than transient exposure of Barrett's oesophageal cells and oesophageal adenocarcinoma cells to acid stimulates proliferation and inhibits apoptosis: as yet the exact mechanisms underlying these effects are unclear but growth promotion and inhibition 
of apoptosis by acid have been described using transformed and non-transformed cell lines and biopsy explants (Souza et al. 2002; Fitzgerald et al. 1996; Kaur and Triadafilopoulos, 2002; Sarosi, Jr. et al. 2005) . Activation of cellular signalling events including the mitogen activated protein (MAP) kinase cascades, activation of protein kinase $\mathrm{C}$, the $\mathrm{Na}^{+} / \mathrm{H}^{+}$exchanger and upregulation of cyclo-oxygenase-2 (COX-2) and prostaglandin $(\mathrm{PG})$ production have all been implicated in the biological responses to acid, although as yet there is no consensus about how these pathways integrate together to regulate the responses to acid (Buttar and Wang, 2004; Souza et al. 2004; Sarosi, Jr. et al. 2005; Kaur and Triadafilopoulos, 2002; Souza et al. 2002).

The mechanisms linking obesity to OAC progression are likely to be multi-factorial but we have hypothesized that increased serum leptin levels may provide a direct link. Leptin is a peptide hormone secreted by adipocytes and serum levels are proportional to body fat mass (Considine et al. 1996). Effects of leptin as a regulator of appetite and body weight are well described but we have recently reported that leptin, at the concentrations seen in obese patients, is a potent growth factor for Barrett's oesophageal adenocarcinoma cells. Using the OE33 cell line we showed that leptin stimulated increased COX-2 mRNA expression and bioactivity via activation the extracellular signal related kinase (ERK), p38 MAP kinase and Akt pathways. Subsequently COX-2 derived PGE2 stimulated cell growth via EP-4 receptormediated transactivation of the epidermal growth factor receptor (EGFR) with downstream activation of c-jun-NH2-terminal kinase (JNK) (Ogunwobi et al. 2006).

Because both acid exposure and leptin individually adversely affect Barrett's epithelial cells in a manner than would be expected to further promote oesophageal 
carcinogenesis, we have hypothesized that leptin and acid exposure may interact directly at the cellular level in OAC to promote growth and/or inhibit apoptosis. We have examined the mechanism of these interactions using the OE33 Barrett's oesophageal adenocarcinoma cell line. This has been used previously as an effective model for studying signalling events in Barrett's OAC and in most cases seems a reasonable model for extrapolating to non-transformed BO (Ogunwobi et al. 2006; Haigh et al. 2003; Tselepis et al. 2003). In particular we have examined the interaction at the level of early signalling events stimulated by leptin and acid responsible for transducing the growth promoting signals. We have concentrated on the MAP kinases, which have been shown to be upregulated in $\mathrm{BO}$ and activated by acid, $\mathrm{COX}-2$ and prostaglandin production, which have been reported to be important factors in the progression of OAC and the epidermal growth factor receptor, which has also been implicated in BO and OAC (Jankowski et al. 1993; Brito et al. 1995; Wilson et al. 1998). 
Methods

\section{Cell culture}

The OE33 Barrett's adenocarcinoma-derived cell line was cultured and subcultured as previously described (Ogunwobi et al. 2006). All cell culture media and supplements were from Invitrogen (Paisley, UK).

\section{Exposure to acid and leptin}

Serum-starved cells were exposed to serum-free DMEM at $\mathrm{pH} 4.0$ for 3 minutes at $37^{\circ} \mathrm{C}$ to stimulate transient gastro-oesophageal reflux (Souza et al. 2002). Control cells were treated with standard serum-free DMEM. After the 3 minutes the medium was changed to fresh serum-free medium supplemented where appropriate with leptin.

\section{3-[4, 5-dimethylthiazol-2-y-l]-2, 5 diphenyltetrazolium bromide (MTT) assay}

OE33 cells were seeded at $5 \times 10^{4}$ cells per well in 48 well plates in $10 \%$ FBS containing medium and allowed to attach for 24 hours. Cells were then serum-starved for 24 hours. Cells were treated with inhibitors, acid and/or leptin and relative cell numbers after 24 hours determined using the MTT colorimetric assay as previously described (Beales, 2004; Ogunwobi et al. 2006).

\section{Bromodeoxyuridine (BrdU) incorporation assay}

OE33 cells were prepared as described previously and after serum-starving for 24 hours cells were then treated with acid and/or leptin and incubated for a further 24 hours. DNA synthesis and relative cell proliferation were assessed using the BrdU incorporation assay (Roche, Mannheim, Germany) (Ogunwobi et al. 2006). 
Assessment of apoptosis

Cells were prepared as for the MTT assay and the serum-starved cells were treated with inhibitors, leptin and/or acid exposure and after 24 hours, the cell death ELISA kit (Roche) was used to quantify intracellular nucleosomes as a measurement of apoptosis as described previously (Ogunwobi and Beales, 2006).

Caspase- 3 activity was quantified in OE33 cell lysates 24 hours after treatment with acid and/or leptin using the caspase-3 colorimetric assay (RandD systems, Abingdon, UK) according to the manufacturer's instructions.

\section{Western blotting}

Lysates from confluent $\mathrm{OE} 33$ cells in $10 \mathrm{~cm}$ Petri dishes were prepared and subjected to electrophoresis and Western blotting as described (Ogunwobi et al. 2006). Antileptin receptor (anti-Ob-R) antibody (H-300: sc-8325, Santa Cruz Biotechnology, CA, USA) was used at 1:200 to detect leptin receptor proteins. Relative density of staining was quantified using the NIH Image for PC image analysis software (Scion Image, freely available from www.scioncorp.com)

\section{COX-2 mRNA assay}

$1 \times 10^{6}$ cells per well were seeded into 12 well plates and cultured in complete culture medium for 48 hours. After 24 hours serum-starvation cells were treated with inhibitors and acid / leptin. Four hours after stimulation the media was aspirated and cells lysed with Cell Lysis Reagent (R and D Systems). COX-2 and glyceraldehyde-3phosphate dehydrogenase (GAPDH) mRNA levels in the cell lysates were measured as described previously using Quantikine ${ }^{\mathrm{TM}}$ mRNA ELISA (R and D Systems) according to the manufacturer's instructions (Ogunwobi et al. 2006). 
PGE2 release

Cells were seeded at $1 \times 10^{5}$ cells per well in 24 well plates and cultured in complete medium for 48 hours. To test for induction of COX-2 activity, cells were serumstarved for 24 hours and then exposed to acid / leptin and incubated for a further 18 hours in serum-free medium. Induced PGE2 production was then assessed as previously described using a specific PGE2 ELISA (R\&D Systems) (Ogunwobi and Beales, 2006).

\section{Detection of activated phosphorylated EGFR and MAP kinases}

$10^{4}$ cells per well were subcultured in 96 well plates for 72 hours and subsequently serum-starved for 24 hours. Cells were then treated with inhibitors for 60 minutes followed by acid / leptin. After stimulation cells were fixed with $4 \%$ formaldehyde. Non-phosphorylated total and active phosphorylated EGFR (tyrosine-1173 phosphorylated), ERK, JNK and p38 MAP kinase were quantified using the FACE ${ }^{\mathrm{TM}}$ ELISA kits (Active Motif, Belgium) as described previously (Ogunwobi and Beales, 2006; Beales and Ogunwobi, 2006).

\section{Leptin receptor ELISA}

Cells were prepared and treated as for kinase phosphorylation assays but formaldehyde fixed 24 hours after acid exposure. Total immunoreative leptin receptor protein was quantified in using a specific cell-based ELISA using previously described methodology (Beales and Ogunwobi, 2006). The primary antibody was 1:250 goat anti-Ob-R (H-300) (Santa Cruz) and quantitation was with a 1:1000 horseradish 
peroxidase conjugated rabbit anti-goat antibody (Sigma, Poole, UK) using $o$ phenylenediamine dihydrochloride as colorimetric substrate (Sigma FAST OPD).

\section{Reagents}

Recombinant human leptin was purchased from Bachem (St Helens, UK), SB 203580 (p38 mitogen activated protein kinase inhibitor) and SP600125 (JNK inhibitor) were purchased from Merck (Nottingham, UK). Glycine-extended gastrin was purchased from Neosystem (Strasburg, France). The selective COX-2 inhibitor NS 398, AG 1478 (EGF receptor kinase (EGFR-kinase) inhibitor) and PD 98059 (p42/44 extracellular signal regulated kinase inhibitor) were from Alexis Biochemicals (Nottingham, UK). All other reagents were from Sigma (Poole, UK). When appropriate, stock solutions of inhibitors were dissolved in dimethyl sulfoxide (DMSO). Inhibitor concentrations were chosen based on published data from our own and others' laboratories (Attoub et al. 2000; Beales, 2004; Ogunwobi et al. 2006). The final concentration of DMSO in experiments was always $<0.1 \%$ and control wells contained an equivalent concentration. Inhibitors were added 60 minutes prior to the acid and /or leptin exposure.

\section{Statistical analysis}

Proliferation studies were done in triplicate or quadruplicate wells. COX-2 mRNA, PGE2 bioactivity and caspase-3 activity studies were performed in duplicate wells with each well assayed in duplicate. Experiments for direct detection of other signalling intermediates were performed in triplicate wells. The mean of all replicates from one experiment were regarded as $\mathrm{N}=1$. Each experiment was repeated 3-6 times. Results are expressed as mean \pm SEM and effects were compared to untreated 
control cells on the same plate. Dose-response curves were analysed using analysis of variance and the paired t-test was used to analyse the effect of inhibitors. A $P$ value $<$ 0.05 was considered significant. 


\section{Results}

\section{Effect of acid and leptin on proliferation}

Leptin alone significantly stimulated OE33 cell proliferation (fig 1a), reliable maximal effects were seen with a concentration of $10 \mathrm{nM}(35 \%$ above basal) and this was used for further studies. Transient exposure to acidic media significantly increased OE33 cell numbers; 24 hours after acid exposure cell numbers had increased by $21 \%$ as assessed by the MTT assay. The combined effect of acid pulse followed by leptin was greater than additive, increasing cell numbers by $63 \%$ (fig $1 \mathrm{~b}$ ). Corresponding effects were seen when proliferation was quantified by measuring DNA synthesis with the BrdU assay: acid (18\%), leptin (41\%) and the combination (67\%) all stimulated proliferation. Once again the effect of the combination of acid and leptin was significantly greater than either alone (fig 1c). For convenience and cost the MTT assay was used for further studies.

To examine the specificity of this growth factor effect of leptin we examined whether another gastrointestinal peptide hormone had similar effects in combination with leptin. Although glycine-extended gastrin itself stimulated proliferation $(1 \mathrm{nM}$ increased cell numbers by $59 \%$ above basal), the combined effect with acid exposure was not significantly different from either stimulant alone (fig 1d).

\section{Effect of acid and leptin on apoptosis}

Acid exposure significantly reduced apoptosis as measured by the intracellular nucleosome ELISA by $21 \%$ and $10 \mathrm{nM}$ leptin inhibited apoptosis by $39 \%$. The combination of the two was synergistic, reducing serum starvation-induced apoptosis by $80 \%$ (fig 2 a). A similar pattern was seen using the assay for caspase- 3 activity: again the combination of acid followed by leptin was significantly more effective than 
either stimulant alone and the reduction was greater than a simply additive effect (fig 2b). Acid alone decrease caspase- 3 activity by $22 \%$ and leptin by $28 \%$ : the combination reduced caspase- 3 activity by $66 \%$.

\section{Effect of acid exposure on leptin receptor protein expression}

To examine whether acid exposure enhances the response to leptin by increasing leptin receptor expression we examined the effect of acid exposure on Ob-R protein levels. 24 hours after transient acid exposure there was no difference in Ob-R protein levels whether assessed by Western blotting (figs 3a \& 3b) or cell-based ELISA (fig 3c). Similar results were seen with both western blotting and ELISA using two other antibodies, Santa Cruz M-18 which recognises both Ob-Ra and Ob-Rb and Santa Cruz $\mathrm{C}-20$ which is specific for the full length $\mathrm{Ob}-\mathrm{Rb}$ isoform (data not shown).

\section{Involvement of COX-2 pathways in the effects of leptin ad acid}

The selective COX-2 inhibitor NS 398 abolished the individual and combined growth promoting and anti-apoptotic effects of acid exposure and leptin (figs $4 \mathrm{a}$ and $4 \mathrm{~b}$ ). However although both acid exposure and leptin treatment individually significantly increased the secretion of COX-2 derived PGE2 (fig 4c) and the level of COX-2 mRNA (fig 4d), there was no difference between the individual effects of leptin and acid. Importantly the combination of acid followed leptin was no more effective that either alone in increasing PGE2 secretion or COX-2 mRNA (figs 4c and 4d).

\section{Effect of acid and leptin on MAP kinase and EGFR activation}

We next examined if the synergistic stimulation of proliferation and inhibition of apoptosis were due to interactions at the level of early kinase signalling events. 
Transient acid exposure was a potent stimulant of immediate phosphorylation of both ERK and the EGFR increasing phosphorylation by $109 \%$ and $60 \%$ respectively. Acid also significantly stimulated p38 MAP kinase activity by $100 \%$ and there was less prominent early activation of JNK ( $46 \%$ above control) (fig 6). Leptin was a potent stimulus to early ERK activation, increasing phosphorylation by $133 \%$ and produced a significant but much smaller increase in p38 MAP kinase activation (45\%) phosphorylation. No early increase in JNK phosphorylation was seen after leptin exposure. The combination of acid exposure followed by leptin stimulated a significantly greater increase in activation of the EGFR and ERK, the combination in both cases being synergistic. Acid followed by leptin increased ERK phosphorylation by $252 \%$ (fig $5 \mathrm{a}$ ) and EGFR phosphorylation by $106 \%$ (fig $5 \mathrm{~d}$ ). However following acid with leptin did not further increase either p38 MAP kinase (fig 5b) or JNK phosphorylation (fig 5c). Initial individual time course studies showed that maximal phosphorylation of all proteins was detectable 2-5 minutes after the addition of each stimulus (data not shown), and subsequent quantitation was performed after 3 minutes of acid or control exposure followed by 3 minutes of leptin or control.

\section{Functional effects of ERK and EGF activation}

To assess whether the synergistic activation of ERK and EGFR by acid and leptin was involved in the proliferative or anti-apoptotic effects we performed experiments in the presence of specific inhibitors of each kinase. The specific ERK inhibitor PD98059 significantly reduced acid-stimulated and leptin-stimulated proliferation as well as abolishing the combined acid + leptin proliferative effect (fig 6a). Similarly AG 1478 the specific EGFR kinase inhibitor blocked the individual and combined effects of acid and leptin on proliferation (fig 6 a). Corresponding results were seen with the 
inhibitors when the anti-apoptotic effects examined; the individual and combined antiapoptotic effects of acid and leptin were clearly dependant on ERK and EGFR activation (fig 6b). Activation of ERK by acid, leptin and the combination was blocked by PD98059 (fig 5a) and studies with AG1478 confirmed that this agent blocked the increase in EGFR phosphorylation stimulated by acid and the acid-leptin combination (fig 5d). 


\section{Discussion}

Here we have demonstrated that short term exposure to acid and treatment with leptin individually stimulated cell proliferation and inhibited serum-starvation induced apoptosis in oesophageal adenocarcinoma cells. Even more striking was the synergistic effects of acid-pulse combined with leptin; the combination reduced apoptosis by $80 \%$. These biological effects required induction of COX-2 and prostaglandin production but the synergistic effects cannot be explained merely by greater induction of COX-2. Integration at the level of early signalling events, with synergistic activation of ERK and the EGFR by the combination of acid and leptin may explain the potent effects and also open up new avenues for treatments or chemoprevention in OAC.

Epidemiologically there are strong links between both obesity and gastro-oesophageal reflux and the development of OAC (Buttar and Wang, 2004; Lagergren et al. 1999a; Lagergren et al. 1999b). The biological mechanisms explaining these as well as the apparent interaction in vivo are not understood. Previous studies using acid exposure in cancerous and non-malignant oesophageal cell lines and biopsy explants have shown that short term acid exposure stimulates cell proliferation and inhibits apoptosis. Various mechanisms have been implicated in these effects, including the $\mathrm{Na}^{+} / \mathrm{H}^{+}$exchangers, MAP kinase activation, COX-2 induction and protein kinase $\mathrm{C}$ activation (Vona-Davis et al. 2005; Souza et al. 2002; Kaur and Triadafilopoulos, 2002). Although there is at present no clear consensus about a definite mechanism integrating these together. Our data are consistent with previous data showing that a short term acid pulse activates MAP kinase pathways, and subsequently downstream of this, COX-2 induction: prostaglandin production is then essential to proliferation and inhibition of apoptosis (Souza et al. 2004). The mechanisms of MAP kinase 
activation and downstream targets of prostaglandins are undetermined at present. Our present data clearly show that an acid-pulse stimulated immediate phosphorylation of the epidermal growth factor receptor and that the specific EGFR kinase inhibitor AG 1478 blocked the proliferative and anti-apoptotic effects of acid. These data show that transactivation of EGFR is an essential early signalling event in the biological responses to acid exposure. Further studies will be necessary to define the precise mechanism of EGFR activation but our data show a novel signalling method activated by acid. Increased expression of EGFR and EGFR ligands has been reported in Barrett's oesophagus and OAC (Jankowski et al. 1993; Brito et al. 1995) and this may provide a basis of a heightened response to acid reflux and so promote the development of cancer in Barrett's oesophagus.

The obesity hormone leptin also stimulated growth and inhibited apoptosis consistent with our previously published data (Ogunwobi et al. 2006). There was a concentration-dependent effect, with effects demonstrable at levels typically seen in obese subjects (Considine et al. 1996). Previous studies have shown that leptin stimulates the growth of a variety of cell types, although in most cases the mechanisms involved are unclear or imprecisely defined. In addition inhibition of cell growth and both pro- and anti-apoptotic effects of leptin have been demonstrated in different models, suggesting there may be some cell and tissue selectivity in these responses (Rouet-Benzineb et al. 2004; Somasundar et al. 2003a; Russo et al. 2004; Somasundar et al. 2003b; Ogunwobi et al. 2006). Preliminary data have recently been reported showing increased leptin receptor expression along the Barrett's oesophagusdysplasia-carcinoma sequence (Bodger et al. 2005) and we have also detected $\mathrm{Ob}-\mathrm{Ra}$ and $\mathrm{Ob}-\mathrm{Rb}$ mRNA and protein expression in the OE19, BIC-1 and FLO oesophageal 
adenocarcinoma cell lines and the $\mathrm{G}_{\mathrm{o}^{-}}, \mathrm{G}_{\mathrm{i}^{-}}, \mathrm{C}$ - and Q-hTERT cell lines derived from dysplastic but non-malignant Barrett's oesophagus (data not shown). Thus it is plausible that in vivo leptin is a growth factor and anti-apoptotic factor for OAC, but it is not possible to determine which receptor isoform is responsible at present.

The most striking finding from our study was the synergistic effects of acid and leptin. This effect seemed relatively specific for leptin, as glycine-extended gastrin (G-Gly), which has been shown to be growth factor for transformed and non-transformed cells elsewhere in the gastrointestinal tract (Ogunwobi and Beales, 2006; Beales and Ogunwobi, 2006; Ferrand et al. 2005), stimulated OE33 cell proliferation but there was no enhancement of effects by combining with acid. Detailed dissection and comparison of the growth promoting actions of leptin and G-Gly is likely to prove useful in determining the mechanisms of the interactions.

Our initial studies with quantitation of leptin receptor expression at the protein level did not show any obvious upregulation of $\mathrm{Ob}-\mathrm{Ra}$ or $\mathrm{Ob}-\mathrm{Rb}$ following acid exposure, suggesting that gross changes in receptor expression did not explain the heightened response to subsequent leptin treatment. We have not yet explored more subtle effects of leptin receptor function such as ligand-binding or internalisation, which could theoretically contribute to the pattern of acid-leptin interactions. However our subsequent demonstration of an enhancement of immediate signalling events by the combination of leptin and acid suggests that changes in overall receptor expression immediately after an acid bolus are unlikely to explain the synergistic actions. 
The COX-2 inhibitor NS 398 abolished the proliferative and anti-apoptotic effects of acid and leptin in isolation as well as the combined effects. These data are consistent with experimental and clinical data showing that COX-2 derived products are very important to the proliferation, inhibition of apoptosis and progression to cancer in Barrett's epithelium (Ogunwobi et al. 2006; Buttar and Wang, 2004). Both an acid pulse and leptin stimulated equivalent increases in COX-2 mRNA and in COX-2derived PGE2 production but the combination of acid and leptin did not further enhance either of these. Thus we conclude that whilst COX-2 is essential to the proliferative and anti-apoptotic effects of the acid-leptin combination, the increased efficacy of the combination cannot be explained by integration at the level of COX-2 induction and PGE2 as a final common pathway. Alternative mechanisms must explain the interaction.

We further explored this by examining early signalling events activated by acid and leptin. It is widely appreciated that activation of the EGFR and the MAP kinase cascades are important means of transducing growth promoting signals in many cell types, and both pro- and anti-apoptotic signals via the different MAP kinase cascades have been demonstrated. In Barrett's oesophagus and OAC the available data suggest ERK, p38 MAP kinase and JNK are important in stimulating cell proliferation and inhibiting apoptosis (Ogunwobi et al. 2006; Souza et al. 2002; Vona-Davis et al. 2005). We have shown that an acid bolus and leptin individually were potent stimulants to ERK activation, but importantly that the combination synergistically activated ERK phosphorylation. Similarly the combination of acid and leptin synergistically activated EGFR phosphorylation. The importance of ERK and EGFR in the biological effects was confirmed as the specific ERK and EGFR inhibitors reduced the proliferative and 
anti-apoptotic effects of the acid-leptin combination. Therefore we conclude that enhanced activation of these pathways is important in mediating the combined effects. Previous studies have implicated both p38 MAP kinase and JNK in the pathogenesis of BO and OAC (Souza et al. 2002) but we did not demonstrate incremental effects with acid and leptin; suggesting that signalling of the combination integrates at the level of ERK and EGFR. As yet the cellular mechanisms responsible this enhanced activation of ERK and EGFR are unclear; these may involve enhanced or differential activation of upstream activators or reduced activities of phosphatases or other inhibitors.

A recent study has shown that acute leptin treatment could transactivate the EGFR in gastric cancer cells, although this effect itself was not associated with a proliferative response (Shida et al. 2005). The current work showed a small but statistically insignificant immediate transactivation of EGFR by leptin alone but this early effect was greatly enhanced by pre-treatment with acid, and inhibitor studies clearly showed that this EGFR activation was associated with cell growth and reduced apoptosis. Previously we showed that leptin alone stimulated relatively late transactivation of the EGFR, detectable 6 hours after leptin treatment and requiring PGE2 production (Ogunwobi et al, 2006): in contrast to the significant immediate activation of the EGFR by the acid and leptin combination in the current work. This transactivation of the EGFR could be an important leptin signal transduction mechanism. Our novel finding of the potentiating effect of an acid bolus, suggests that this mechanism may be particularly important in obese patients in vivo, where the cells are intermittently exposed to acid reflux on a background of increased circulating leptin. 
Interestingly the ERK and EGFR inhibitors abolished the proliferative effects of acidleptin but although significant reversal of the anti-apoptotic effect wase seen, acidleptin still significantly reduced serum-starvation in the presence of either inhibitor, suggesting other pathways (such as Akt, protein kinase C or STAT proteins) may be specifically important in the anti-apoptotic effects.

The current studies were performed in the OE33 adenocarcinoma cell line and suggest that acid and leptin together promote tumour growth. The signal transduction mechanisms in this, and other OAC cell lines, have been well described and in general seem similar to those described in both biopsy explants and Barrett's oesophagus in vivo (Souza et al. 2002, Haigh et al. 2003; Tselepis et al. 2003): because of the intrinsic genetic differences seen in established malignant cancer cell lines, it is not possible to directly extrapolate to the pre-malignant stage and further studies including the use of non-transformed dysplastic Barrett's cell lines and biopsy explants are required to follow up these findings (Feagins et al. 2007).

Leptin also stimulates the growth of a variety of other cell lines that express leptin receptors including colon cancer and breast cancer cells (Ogunwobi and Beales 2007, Dieudonne et al. 2002). The potentiation of leptin-induced signalling by acid may be a more general biological phenomena but in vivo the oesophagus is the only tissue where exposure to acid is both biologically plausible and pathophysiological. Therefore the findings on the interactions of leptin and acid are mainly directly relevant to the oesophagus. 
We believe that the combination of intermittent acid exposure from gastrooeosphageal reflux combined with increased circulating leptin in obesity may provide an explanation of the observation that reflux and increased body mass index independently increase the risk of OAC but the combination is worse than either alone. We conclude that induction of COX-2 is essential to the proliferative and antiapoptotic effects and that synergistic activation of ERK and EGFR provides a biological basis for the interaction of acid and leptin in promoting the growth of oesophageal adenocarcinoma. 


\section{References}

Attoub, S., Noe, V., Pirola, L., Bruyneel, E., Chastre, E., Mareel, M., Wymann, M.P. and Gespach, C. (2000) Leptin promotes invasiveness of kidney and colonic epithelial cells via phosphoinositide 3-kinase-, rho-, and rac-dependent signaling pathways. FASEB J 14, 2329-38.

Beales, I.L. (2004) Gastrin and interleukin-1beta stimulate growth factor secretion from cultured rabbit gastric parietal cells. Life Sci. 75, 2983-95.

Beales, I.L. and Ogunwobi, O. (2006) Glycine-extended gastrin inhibits apoptosis in colon cancer cells via separate activation of Akt and JNK pathways. Mol Cell Endocrinol. 247, 140-9.

Bodger, K., Ahmed, S. and Pazmany, L. (2005) Over-expression of the leptin receptor in Barrett's metaplasia and cancer. Gut 54, A70(Abstract)

Brito, M.J., Filipe, M.I., Linehan, J. and Jankowski, J. (1995) Association of transforming growth factor alpha (TGFA) and its precursors with malignant change in Barrett's epithelium: biological and clinical variables. Int. J Cancer 60, 27-32.

Buttar, N.S. and Wang, K.K. (2004) Mechanisms of disease: Carcinogenesis in Barrett's esophagus. Nat. Clin. Pract. Gastroenterol. Hepatol. 1, 106-12.

Considine, R.V., Sinha, M.K., Heiman, M.L., Kriauciunas, A., Stephens, T.W., Nyce, M.R., Ohannesian, J.P., Marco, C.C., McKee, L.J., Bauer, T.L. and Caro, J.F. (1996) 
Serum immunoreactive-leptin concentrations in normal-weight and obese humans. $N$. Engl. J Med 334, 292-5.

Dieudonne MN, Machinal-Quelin F, Serazin-Leroy V, Leneveu MC, Pecquery R, Giudicelli Y (2002). Leptin mediates a proliferative response in human MCF7 breast cancer cells. Biochem Biophys Res Commun. 293, 622-8.

Feagins LA, Zhang HY, Hormi-Carver K, Quinones MH, Thomas D, Zhang X, Terada LS, Spechler SJ, Ramirez RD, Souza RF (2007). Acid has antiproliferative effects in nonneoplastic Barrett's epithelial cells. Am J Gastroenterol. 102, 10-20.

Ferrand, A., Bertrand, C., Portolan, G., Cui, G., Carlson, J., Pradayrol, L., Fourmy, D., Dufresne, M., Wang, T.C. and Seva, C. (2005) Signaling pathways associated with colonic mucosa hyperproliferation in mice overexpressing gastrin precursors. Cancer Res. 65, 2770-7.

Fitzgerald, R.C., Omary, M.B. and Triadafilopoulos, G. (1996) Dynamic effects of acid on Barrett's esophagus. An ex vivo proliferation and differentiation model. J Clin. Invest. 98, 2120-8.

Haigh, C.R., Attwood, S.E., Thompson, D.G., Jankowski, J.A., Kirton, C.M., Pritchard, D.M., Varro, A. and Dimaline, R. (2003) Gastrin induces proliferation in Barrett's metaplasia through activation of the CCK2 receptor. Gastroenterology 124, 615-25. 
Jankowski, J., Hopwood, D., Pringle, R. and Wormsley, K.G. (1993) Increased expression of epidermal growth factor receptors in Barrett's esophagus associated with alkaline reflux: a putative model for carcinogenesis. Am. J Gastroenterol. 88, 402-8.

Jemal, A., Murray, T., Ward, E., Samuels, A., Tiwari, R.C., Ghafoor, A., Feuer, E.J. and Thun, M.J. (2006) Cancer statistics, 2005. CA. Cancer J Clin. 55, 10-30.

Kaur, B.S. and Triadafilopoulos, G. (2002) Acid- and bile-induced PGE(2) release and hyperproliferation in Barrett's esophagus are COX-2 and PKC-epsilon dependent. Am. J Physiol. Gastrointest. Liver Physiol. 283, G327-34.

Lagergren, J., Bergstrom, R., Lindgren, A. and Nyren, O. (1999a) Symptomatic gastroesophageal reflux as a risk factor for esophageal adenocarcinoma. N. Engl. J Med 340, 825-31.

Lagergren, J., Bergstrom, R. and Nyren, O. (1999b) Association between body mass and adenocarcinoma of the esophagus and gastric cardia. Ann. Intern. Med 130, 88390.

Ogunwobi, O., Mutungi, G. and Beales, I.L. (2006) Leptin stimulates proliferation and inhibits apoptosis in Barrett's esophageal adenocarcinoma cells by cyclooxygenase-2dependent, prostaglandin-E2-mediated transactivation of the epidermal growth factor receptor and c-Jun NH2-terminal kinase activation. Endocrinology. 147, 4505-16. 
Ogunwobi, O.O. and Beales, I.L. (2006) Glycine-extended gastrin stimulates proliferation and inhibits apoptosis in colon cancer cells via cyclo-oxygenaseindependent pathways. Regul. Pept. 134, 1-8.

Ogunwobi O.O. and Beales IL (2007) The anti-apoptotic and growth stimulatory actions of leptin in human colon cancer cells involves activation of JNK mitogen activated protein kinase, JAK2 and PI3 kinase/Akt. Int J Colorectal Dis 22, 401-9

Rouet-Benzineb, P., Aparicio, T., Guilmeau, S., Pouzet, C., Descatoire, V., Buyse, M. and Bado, A. (2004) Leptin counteracts sodium butyrate-induced apoptosis in human colon cancer HT-29 cells via NF-kappaB signaling. J Biol. Chem. 279, 16495-502.

Russo, V.C., Metaxas, S., Kobayashi, K., Harris, M. and Werther, G.A. (2004) Antiapoptotic effects of leptin in human neuroblastoma cells. Endocrinology 145, 4103-12.

Sarosi, G.A., Jr., Jaiswal, K., Herndon, E., Lopez-Guzman, C., Spechler, S.J. and Souza, R.F. (2005) Acid increases MAPK-mediated proliferation in Barrett's esophageal adenocarcinoma cells via intracellular acidification through a $\mathrm{Cl}-/ \mathrm{HCO} 3-$ exchanger. Am. J Physiol. Gastrointest. Liver Physiol. 289, G991-6.

Shida, D., Kitayama, J., Mori, K., Watanabe, T. and Nagawa, H. (2005) Transactivation of epidermal growth factor receptor is involved in leptin-induced activation of janus-activated kinase 2 and extracellular signal-regulated kinase $1 / 2$ in human gastric cancer cells. Cancer Res. 65, 9159-63. 
Somasundar, P., Riggs, D., Jackson, B., Vona-Davis, L. and McFadden, D.W. (2003a) Leptin stimulates esophageal adenocarcinoma growth by nonapoptotic mechanisms. Am. J Surg. 186, 575-8.

Somasundar, P., Yu, A.K., Vona-Davis, L. and McFadden, D.W. (2003b) Differential effects of leptin on cancer in vitro. J Surg. Res. 113, 50-5.

Souza, R.F., Shewmake, K., Terada, L.S. and Spechler, S.J. (2002) Acid exposure activates the mitogen-activated protein kinase pathways in Barrett's esophagus. Gastroenterology 122, 299-307.

Souza, R.F., Shewmake, K., Pearson, S., Sarosi, G.A., Jr., Feagins, L.A., Ramirez, R.D., Terada, L.S. and Spechler, S.J. (2004) Acid increases proliferation via ERK and p38 MAPK-mediated increases in cyclooxygenase-2 in Barrett's adenocarcinoma cells. Am. J Physiol. Gastrointest. Liver Physiol. 287, G743-8.

Tselepis, C., Morris, C.D., Wakelin, D., Hardy, R., Perry, I., Luong, Q.T., Harper, E., Harrison, R., Attwood, S.E. and Jankowski, J.A. (2003) Upregulation of the oncogene c-myc in Barrett's adenocarcinoma: induction of c-myc by acidified bile acid in vitro.

Gut 52, 174-80.

Vona-Davis, L., Frankenberry, K., Cunningham, C., Riggs, D.R., Jackson, B.J., Szwerc, M.F. and McFadden, D.W. (2005) MAPK and PI3K inhibition reduces proliferation of Barrett's adenocarcinoma in vitro. $J$ Surg. Res. 127, 53-8. 
Wilson, K.T., Fu, S., Ramanujam, K.S. and Meltzer, S.J. (1998) Increased expression of inducible nitric oxide synthase and cyclooxygenase- 2 in Barrett's esophagus and associated adenocarcinomas. Cancer Res. 58, 2929-34. 


\section{Figure legends}

\section{Fig 1: Effect of leptin and acid on cell proliferation in OE33 cells}

Serum-starved OE33 cells were treated with increasing concentrations of leptin and relative cell numbers quantified after 24 hours with the MTT colormetric assay (Fig 1a). Serum-starved cells were treated with a 3 minute acid $\mathrm{pH} 4.0$ pulse followed by control medium (acid), a 3 minute control pulse followed by leptin $10 \mathrm{nM}$ for 24 hours (leptin) or acid pulse followed by leptin (acid + leptin). After 24 hours cell proliferation was assessed with the MTT assay (fig 1b) or BrdU incorporation (fig 1c). Identically treated cells were exposed to acid bolus and/or glycine-extended gastrin (G-Gly $1 \mathrm{nM}$ ) instead of leptin and relative cell numbers assessed after 24 hours with the MTT assay (fig 1d). All results expressed as mean \pm SEM, relative to cells treated only with control media, $\mathrm{N}=3-6 .{ }^{*} P<0.05$ vs control, ${ }^{* *} P<0.01$ vs control, ${ }^{\#} P<$

0.05 vs acid or leptin alone, ${ }^{\# \#} P<0.01$ vs acid or leptin alone.

\section{Fig 2: Effect of acid and leptin on OE33 cell apoptosis}

Serum-starved OE33 cells were treated with either a 3 minute $\mathrm{pH} 4.0$ acid pulse followed by control medium (acid), a control medium pulse followed by $10 \mathrm{nM}$ leptin for 24 hours (leptin) or acid pulse followed by leptin (acid + leptin) Fig 2a: Apoptosis after 24 hours was quantified by ELISA of intracellular nucleosomes $(\mathrm{N}=6)$. Fig $\mathbf{2 b}$ : Caspase- 3 activity in cell lysates after 24 hours was quantified by a colorimetric assay $(\mathrm{N}=3)$. Results expressed as mean apoptosis or caspase-3 activity $\pm \mathrm{SEM}$ compared control cells treated with only serum-free medium, ${ }^{*} P<0.05$ vs control, ${ }^{* *} P<0.01$ vs control, ${ }^{\#} P<0.05$ vs acid or leptin alone, ${ }^{\# \#} P<0.01$ vs acid or leptin alone.

\section{Fig 3: Effect of acid pulse on leptin receptor protein levels}


Serum-starved OE33 cells were treated with a 3 minute $\mathrm{pH} 4.0$ acid pulse followed by serum-free medium for 24 hours or treated with only control serum-free medium. Fig 3a, after 24 hours leptin receptor protein expression was visualised in whole cell lysates by western blotting with anti-Ob-R antibody. COLO 320DM cell lysate was used a positive control. Representative western blot shown. Fig 3b, Relative expression of leptin receptor protein assessed by densitometry of western blots, mean $\pm \mathrm{SEM}, \mathrm{N}=4$. Fig $3 \mathbf{c}$, after 24 hours cells were formalin fixed and total $\mathrm{Ob}-\mathrm{R}$ quantified using a cell-based ELISA. Results were normalised for total cell number in each well by crystal violet staining. Results expressed as the OD $450 \mathrm{~nm} / 550 \mathrm{~nm}$, which is equivalent to specific binding / cell number. Mean $\pm \mathrm{SEM}, \mathrm{N}=3$.

\section{Fig 4: Involvement of $C O X-2$ and PGE2 in the proliferative and anti-apoptotic}

\section{effects of acid and leptin}

Serum starved OE33 cells were treated with a 3 minute $\mathrm{pH} 4.0$ acid pulse followed by control medium, a control pulse followed by $10 \mathrm{nM}$ leptin for 4,18 or 24 hours or the acid-pulse followed by leptin for the same time periods.

Fig 4a: After 24 hours relative cell numbers were quantified by MTT assay. Results are expressed as cell numbers compared to identically treated control cells, mean \pm SEM, $\mathrm{N}=5, * P<0.05$ vs stimulant in the absence of NS $398, * * P<0.01 \mathrm{vs}$ stimulus alone in absence of NS 398.

Fig 4b: After 24 hours apoptosis was quantified by intracellular nucleosome ELISA. Results are expressed as apoptosis compared to identically treated control cells, mean $\pm \mathrm{SEM}, \mathrm{N}=3, * P<0.05$ vs stimulant in the absence of NS $398, * * P<0.01$ vs stimulus alone in absence of NS 398. 
Fig 4c: After 18 h hours PGE2 secretion was measured by a specific ELISA. Results are expressed as PGE2 secreted. Mean $\pm \mathrm{SEM}, \mathrm{N}=3, * P<0.05$ vs control, $* * P<$ 0.01 vs control, ${ }^{\#} P<0.05$ vs secretion in absence of NS 398, ${ }^{\# \#} P<0.01$ vs secretion in absence of NS 398 .

Fig 4d: After 4 hours COX-2 mRNA levels were quantified by ELISA. Results are normalised to GAPDH mRNA expression, also quantified by ELISA and expressed as ratio of control cells. Mean $\pm \mathrm{SEM}, \mathrm{N}=3, * P<0.05$ vs control, ${ }^{* *} P<0.01$ vs control

\section{Fig 5: Effect of acid and leptin on early kinase signalling events}

Serum starved OE33 cells were treated with either a 3 minute $\mathrm{pH} 4.0$ acid pulse followed by 3 minutes of serum-free medium, a 3 minute control pulse followed by leptin $10 \mathrm{nM}$, or acid followed by leptin. 3 minutes after addition of leptin cells were formalin fixed and subsequently active phosphorylated kinase and total kinase levels quantified in fixed cells using specific cell based ELISAs. Results for each well were normalised for cell content using subsequent crystal violet staining. Results are expressed as the ratio of phosphorylated / total kinase relative to control-treated cells. Where indicated inhibitors (PD $9805925 \mu \mathrm{M}, \mathrm{SB} 2035805 \mu \mathrm{M}, \mathrm{SP} 60012510 \mu \mathrm{M}$ or AG $1478250 \mathrm{nM}$ ) were added to serum starved cells 60 minutes prior to experimental procedures. Fig 5a: effect of ERK phosphorylation, Fig 5b: effect on p38 MAP kinase phosphorylation, Fig 5c: effect on JNK phosphorylation, Fig 5d: effect on EGFR phosphorylation, mean $\pm \mathrm{SEM}, \mathrm{N}=4, * P<0.05$ vs control, $* * P<0.01$ vs control, $\uparrow \dagger \uparrow P<0.05$ vs acid or leptin alone, ${ }^{\#} P<0.05$ vs phosphorylation in absence of specific inhibitor, ${ }^{\#} P<0.01$ vs phosphorylation in absence of specific inhibitor. 
Fig 6: Involvement of ERK and EGFR in the proliferative and antiapoptotic effects of acid and leptin

Serum starved OE33 cells were treated with either a $3 \mathrm{~min} p H 4.0$ acid or control bolus followed by 24 hours $10 \mathrm{nM}$ leptin or control. After 24 hours relative cell numbers were assessed by MTT assay (fig 6a: top) and apoptosis by nucleosome ELISA (fig 6b: bottom). Where indicated cells were pretreated with PD $9805925 \mu \mathrm{M}$ or AG $1478250 \mathrm{nM}$ for 60 mins before experimental exposures. Results are expressed as percentage of identically control treated cells on the same plate, mean $\pm \mathrm{SEM}, \mathrm{N}=$ $3-6, * P<0.05$ vs result in the absence of inhibitor, $* * P<0.01$ vs result in the absence of inhibitor. 


\title{
Funding:
}

Grant support for this work was provided by The Norfolk and Norwich Hospital

Bicentenary Trust, The Royal Society, The Peel Medical Research Trust, Mason

Medical Research Foundation, Big C Cancer Charity, The Institute of Biomedical

Science and NHS Research and Development funding.

The authors have no conflict of interests relevant to the research reported in this manuscript.

\section{Acknowledgments:}

We would like to thank Patricia Lunness for technical assistance.

\begin{abstract}
presentation:
Part of this work was presented in abstract form at the United European

Gastroenterology Week, Copenhagen, 2005 and published in abstract form (Gut (2005) 54 (Supp VII): A70.
\end{abstract}



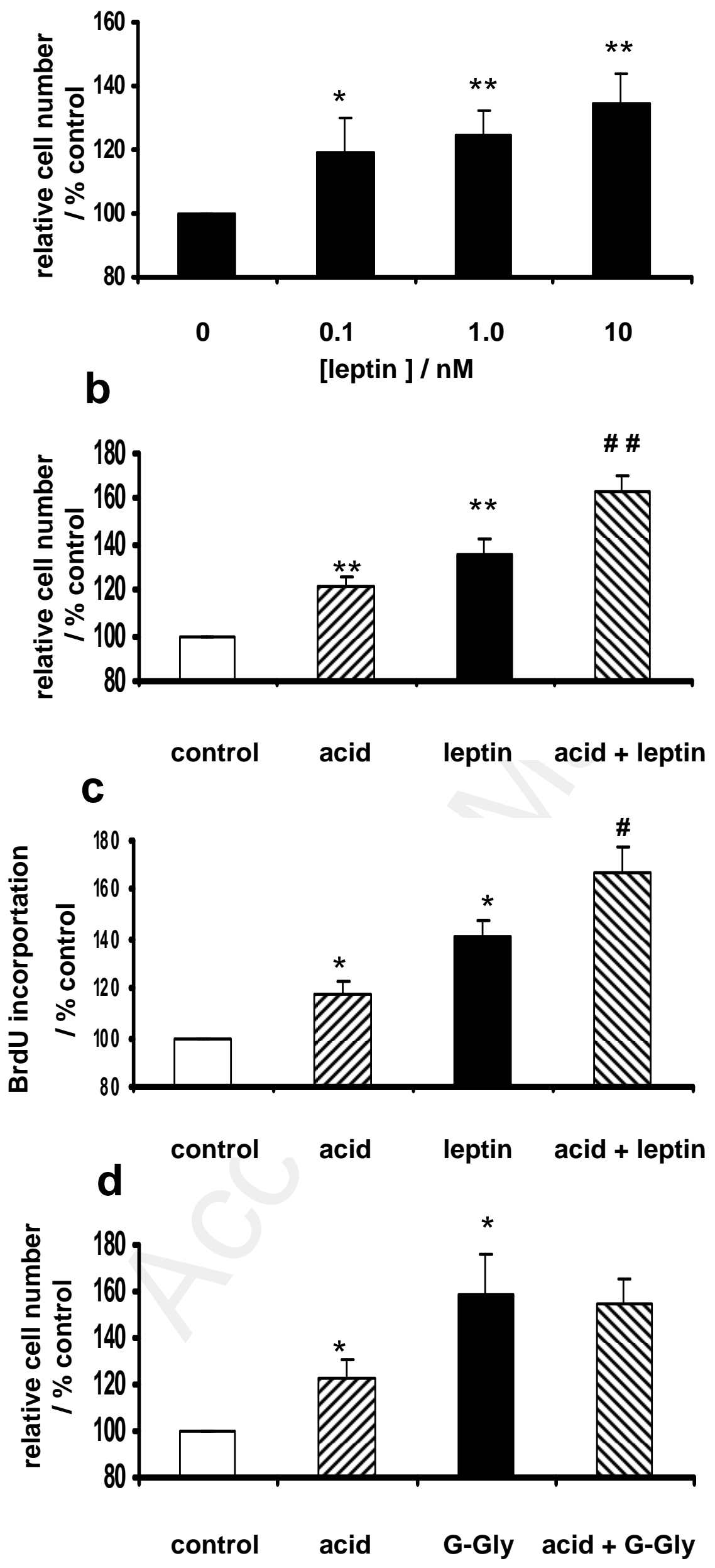

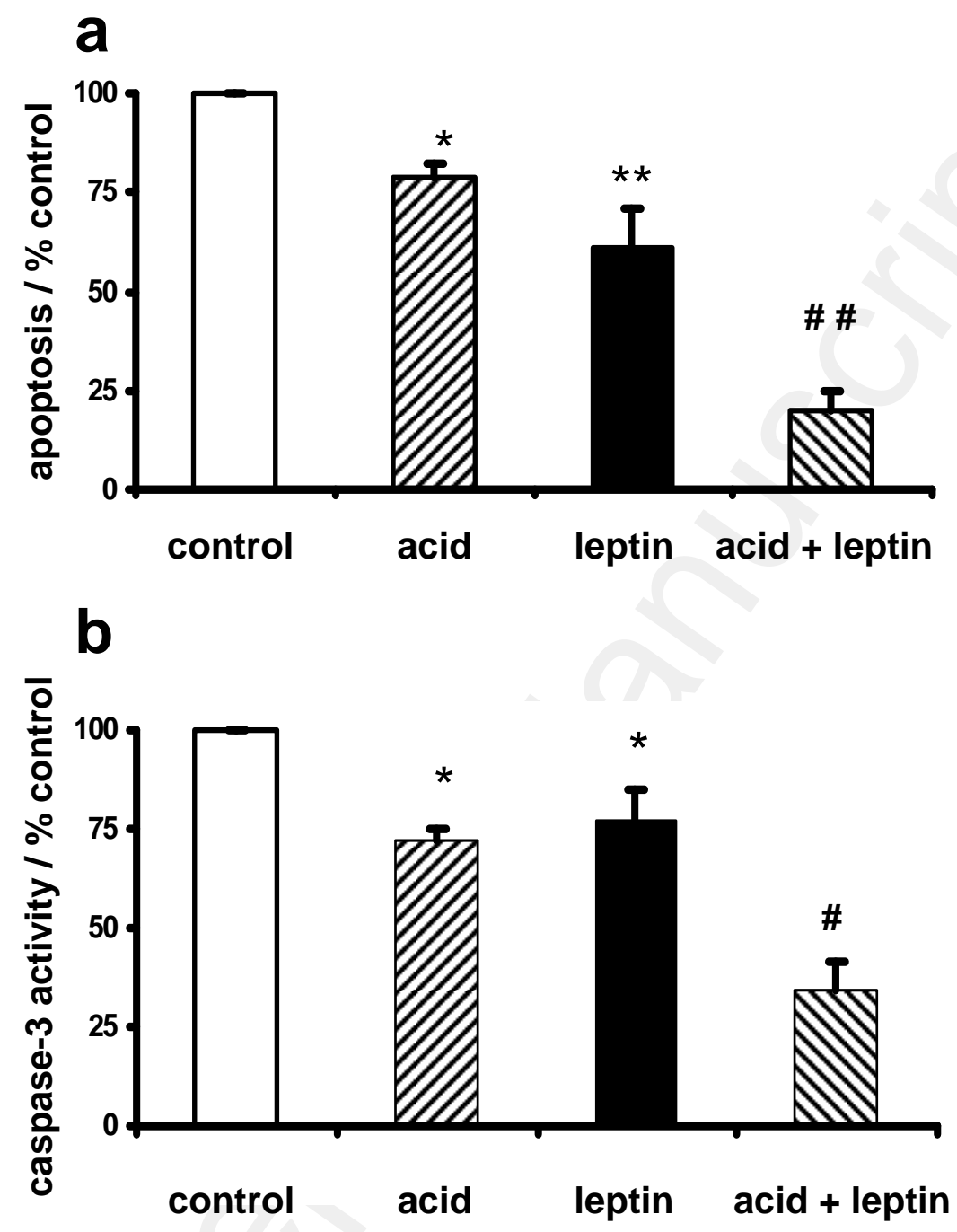

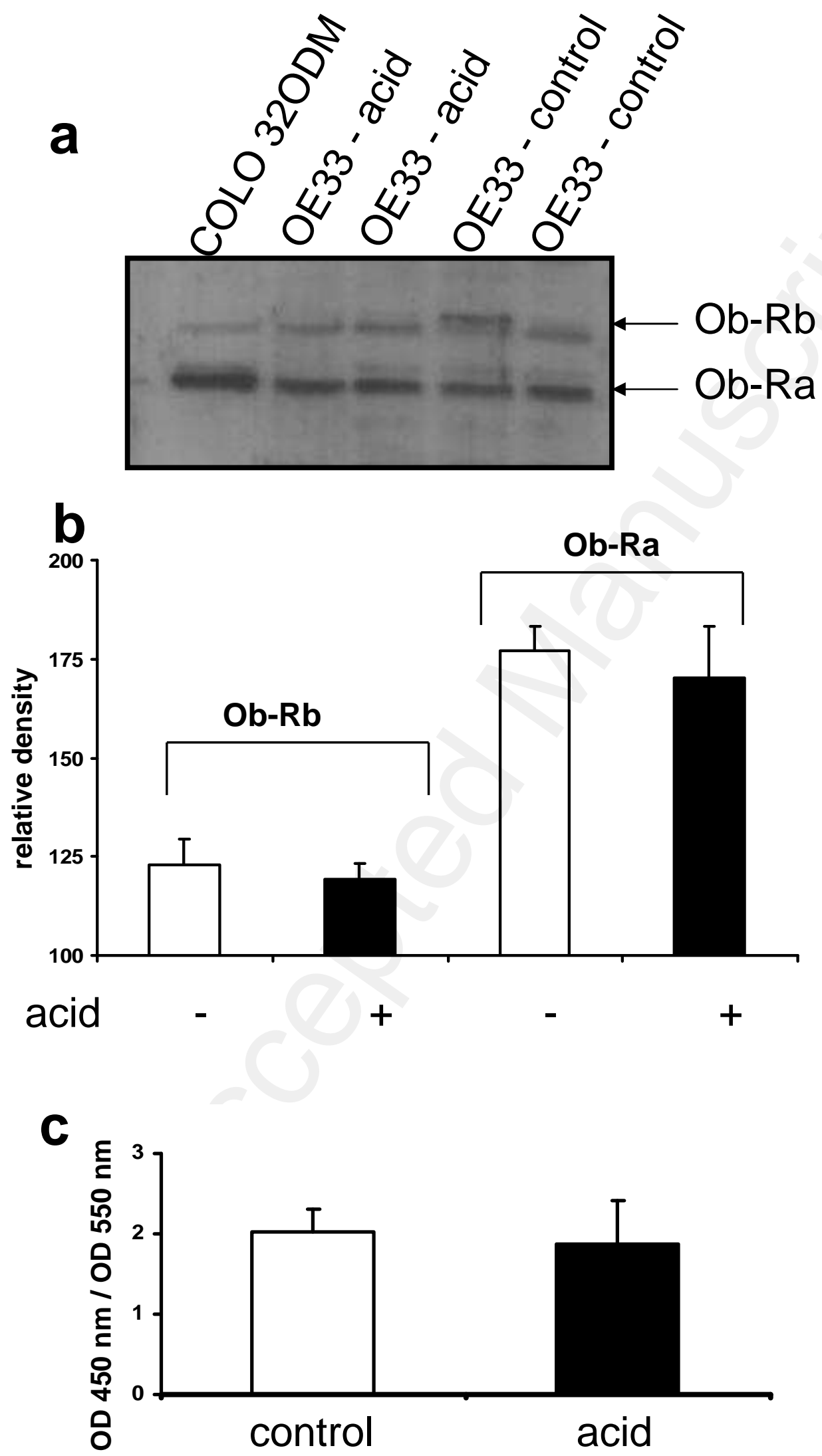

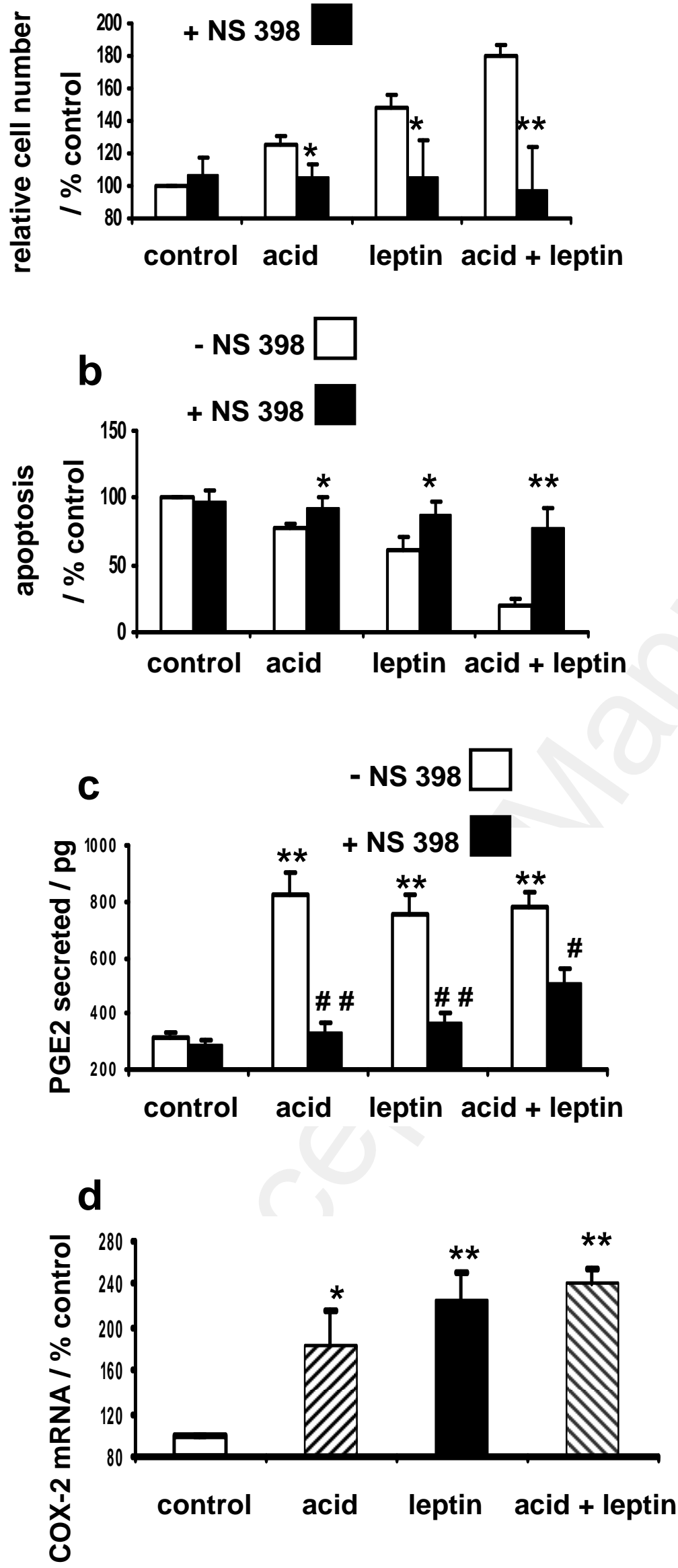

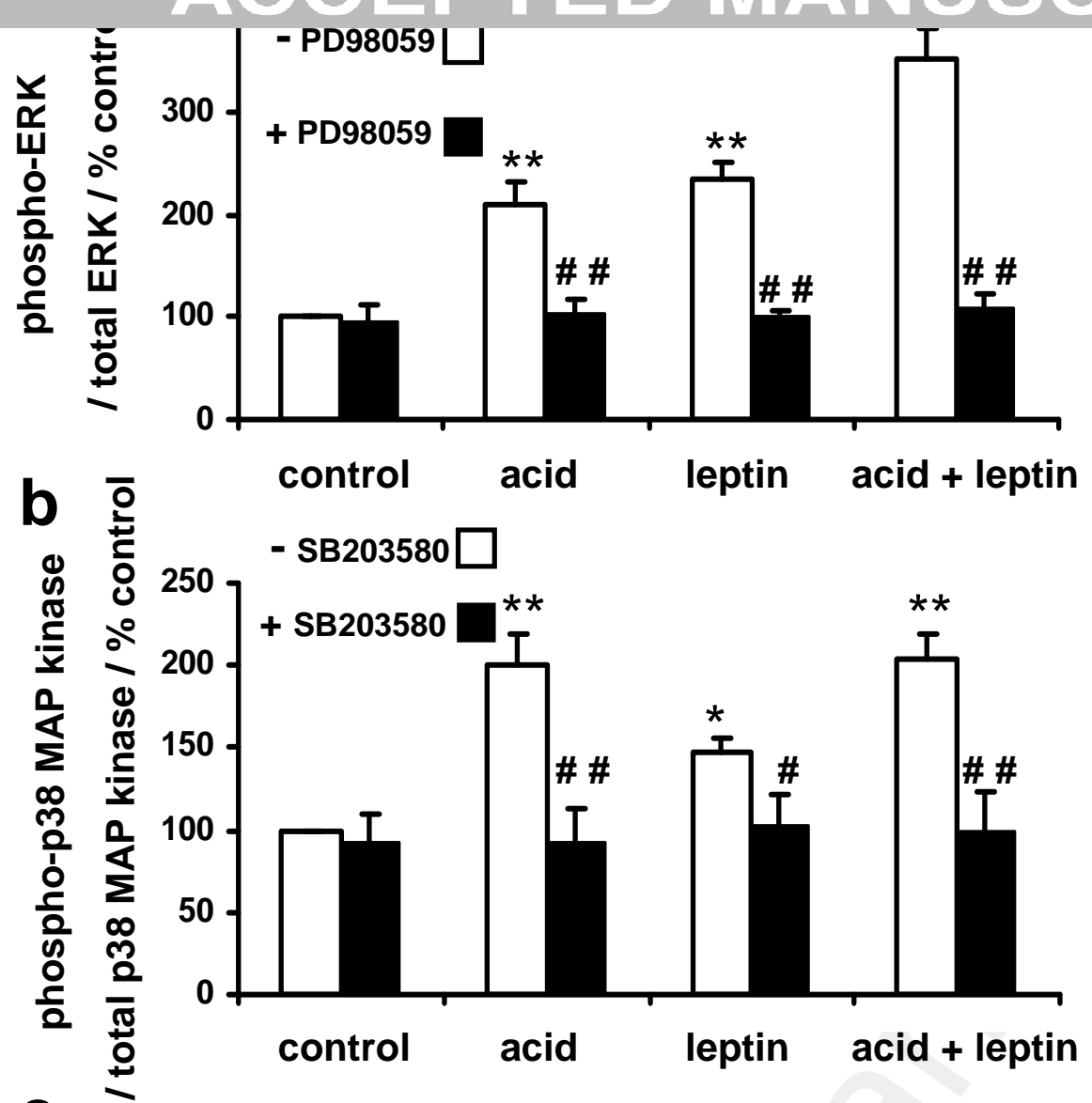

C

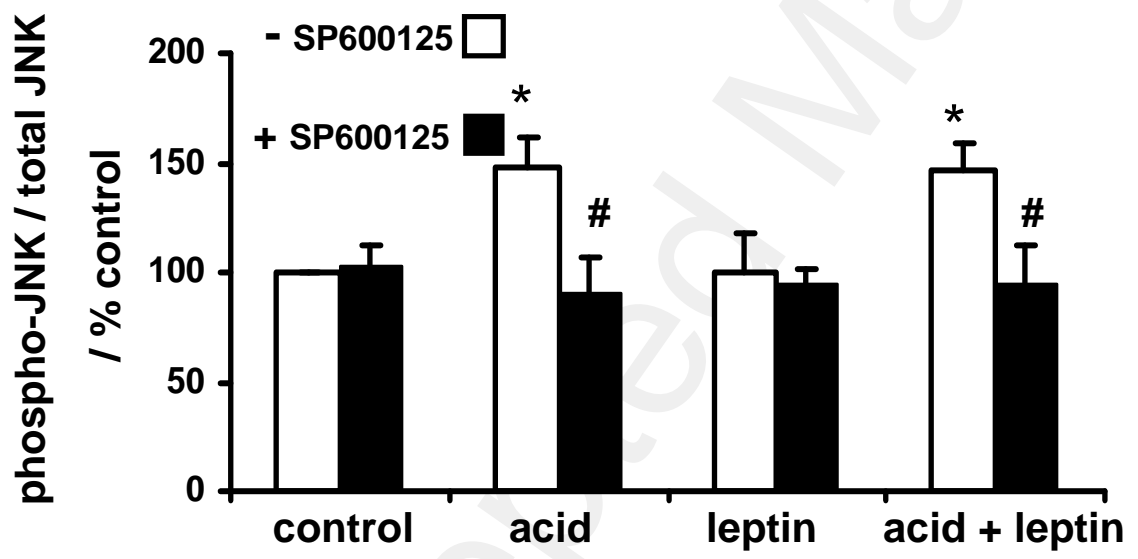

d

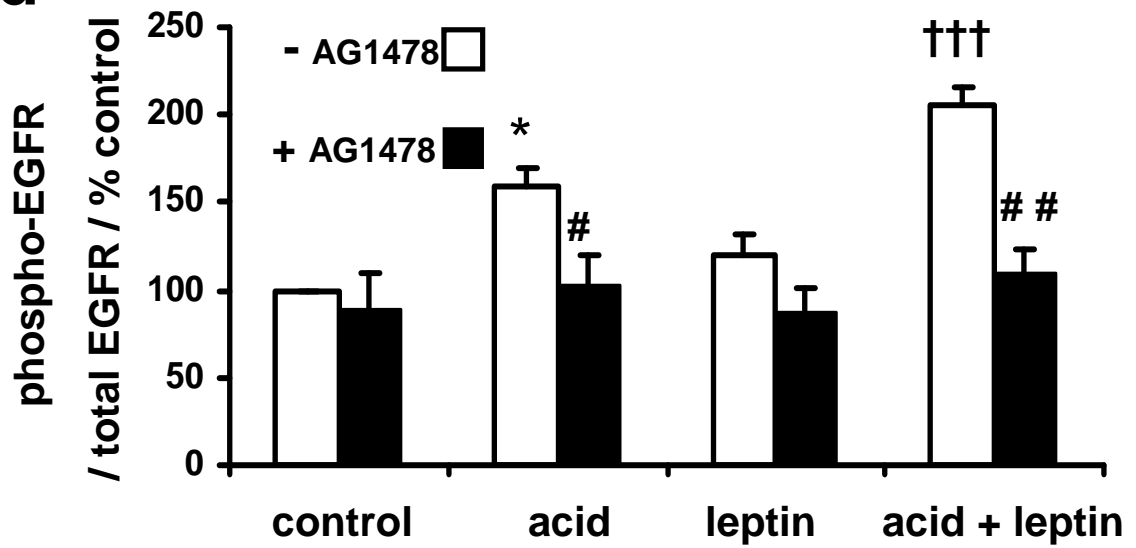



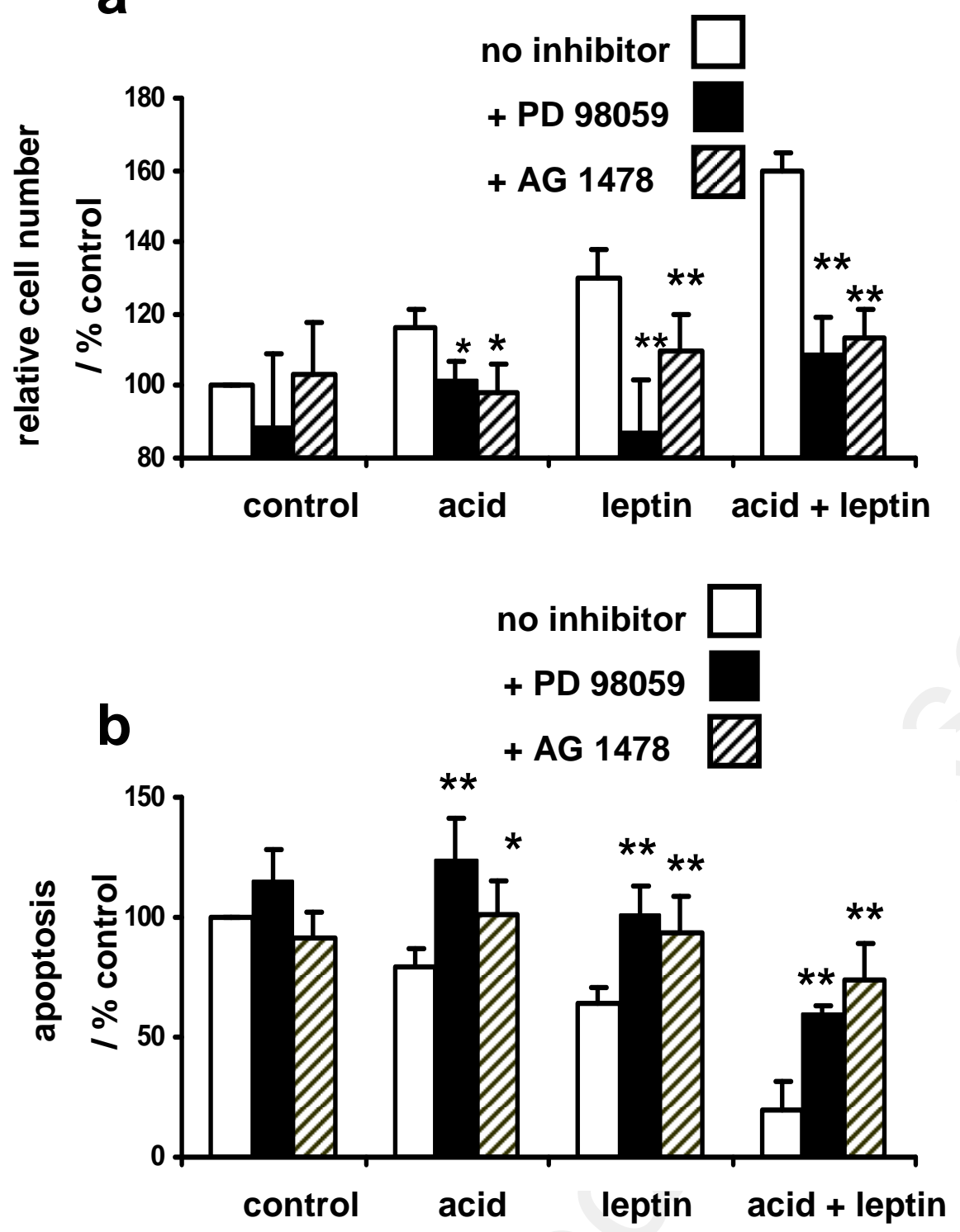